\title{
Solving cell infiltration limitations of electrospun nanofiber meshes for tissue engineering applications
}

\begin{abstract}
Aim: Utilize the dual composition strategy to increase the pore size and solve the low cell infiltration capacity on random nanofiber meshes, an intrinsic limitation of electrospun scaffolds for tissue engineering applications. Materials \& methods: Polycaprolactone and poly(ethylene oxide) solutions were electrospun simultaneously to obtain a dual composition nanofiber mesh. Selective dissolution of the poly(ethylene oxide) nanofiber fraction was performed. The biologic performance of these enhanced pore size nanofibrous structures was assessed with human osteoblastic cells. Results: The electrospun nanofiber meshes, after the poly(ethylene oxide) dissolution, showed statistically significant larger pore sizes when compared with polycaprolactone nanofiber meshes with a similar polycaprolactone volume fraction. This was also confirmed by interferometric optical profilometry. Using scanning electron microscopy and laser scanning confocal microscopy, it was observed that osteoblastic cells could penetrate into the nanofibrous structure and migrate into the opposite and unseeded side of the mesh. Conclusion: An electrospun mesh was created with sufficient pore size to allow cell infiltration into its structure, thus resulting in a fully populated construct appropriate for 3D tissue engineering applications.
\end{abstract}

\section{KEYWORDS: biodegradable scaffold cell penetration electrospun nanofiber mesh pore size tissue enginnering}

Tissue engineering is an emergent research area that offers the promise of tissue regeneration, relevant for many clinical conditions. The success of tissue engineering is highly dependent on a scaffold that will act as a temporary matrix for cell proliferation and extracellular matrix (ECM) deposition, with consequent tissue in-growth until the new tissue is totally regenerated [1]. Therefore, an appropriate 3D scaffold (taking into account its biocompatibility, pore size, porosity and interconnectivity, biodegradability, and adequate surface chemistry and mechanical properties) is an essential component for a tissue engineering strategy $[2,3]$. Polymers are believed to be the ideal material for tissue engineering applications. Both natural and synthetic origin polymers can be applied in this kind of strategy. Much of the current research is focused on natural materials due to their improved biocompatibility (e.g., collagen [4-6], fibrinogen [7], chitosan [8-10], starch [11-13], hyaluronic acid [14,15] and poly[hydroxybutyrate]) [16]. Synthetic biodegradable polymers are the ones that are more commonly used within the biomedical engineering field. Their chemical versatility and processability varies according to their structure and nature.

Besides the choice of adequate materials, the macro- and micro-structural properties of the materials are of utmost importance. It is very important that the scaffold can mimic, as much as possible, the physicochemical cues provided by the ECM, in order to guide communities of cells to rebuild the native tissue structure [17-21]. In many tissues, cells are surrounded by an intricate network of protein fibrils and interwoven fibers within a hydrated network of glycosaminoglycan chains that determine the physical properties of the tissue [22]. Those components produce an interconnected nano- or micro-ranged fibrous network within the ECM. The ECM provides an appropriate microenvironment for cells, controls the tissue structure and regulates many cellular functions, including the adhesion, migration and proliferation to maintain the tissue structure. The ECM is also responsible for transmitting signals to cell membrane receptors, and orchestrates the controlled release of growth factors and signaling molecules that regulate the structure and function of the tissue [22-24].

A series of processing techniques, such as solvent casting [25], fiber bonding [26,27], wet spinning [28], melt-based technologies [12,29], high pressure-based methods [30,31], freeze drying [32] and rapid prototyping technologies [33-35], were developed with the aim of producing scaffolds with adequate properties for tissue engineering. Electrospinning has attracted great attention in the field of tissue engineering, since the produced structures are composed by nanoscale (or more correctly submicron) fibers with
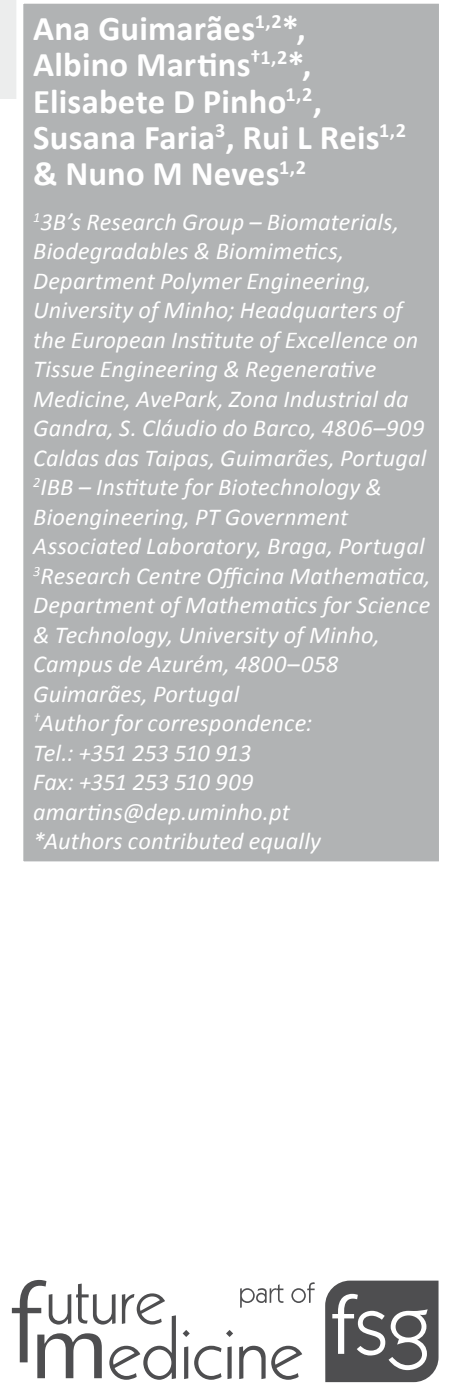
interconnected micropores and a high surface to volume ratio, which show features that are similar to the topographic characteristics of the ECM [17,23,36]. In addition, electrospinning is a relatively versatile polymer processing technique, in the sense that several polymeric blends and compositions with other materials or additives (e.g., growth factors and other cell regulatory biomolecules), along with proteins [37] and living cells [38,39], can be used to develop functionally active nanofibrous structures. The electrospinning process is based on the application of an electric field, generated by a high voltage power supply applied between a polymeric solution and a metal ground collector. When the electric field reaches a critical value, the electrostatic force overcomes the surface tension of the polymeric solution and a charged polymer jet is ejected from the capillary tip of the needle. As the jet travels towards the grounded collector, it undergoes a stretching process together with a fast solvent evaporation. This process results in the formation of a random nonwoven mesh composed of solid and long nanofibers $[40,41]$. The remaining solvent in the fibers allows for the establishment of links between successive layers of the fibers in the mesh.

Despite all the advantages of using electrospun scaffolds for tissue engineering applications, these meshes have a major limitation. The pores formed in the electrospun fibrous meshes typically do not allow cell infiltration into the inner regions of the structure. This is a major shortcoming of the structures and compromises the potential use of electrospun nanofiber meshes [17]. Much research has focused on the development of fibers with smaller diameters to maximize surface area. However, it was demonstrated that the mean pore radius varies directly with the fiber diameter, leading to smaller pore size [42]. Thus, the nanofiber mesh will essentially behave as a $2 \mathrm{D}$ sheet where the cells can only proliferate at the surface, instead of allowing a 3D structure where cells are able to infiltrate. Some tissues may still benefit from such 2D structures but most tissues need 3D structuring. The use of porogen agents, such as salt particles [43,44], chemical blowing agents [45] or postprocessing by laser machinery [46] are other possible strategies already described in the literature, aiming at increasing the pore size of electrospun meshes. In the referred salt leaching technique, salt particles are deposited layer by layer, which causes delamination of the nanofiber scaffold. The structures obtained still have limitations regarding cell infiltration, since this only takes place through the lateral side of the scaffold and not across the thickness of the nanofiber mesh [43]. By using a blowing agent, pores are created in discrete points of the mesh, but cellular infiltration is not fully demonstrated [45]. Laser post-processing is also capable of producing localized cavities or channels in the nanofiber meshes. Biological assays were not yet reported to verify the extent of cell infiltration through those laser-processed holes in the mesh structure [46].

In this article we present a different strategy to increase the pore size of electrospun nanofibers meshes consisting of the creation of a dual composition (two types of polymer nanofibers produced simultaneously) nonwoven nanofiber mesh. After the production of the mesh, one of these polymers was selectively removed, in order to increase the void volume and consequently the pore size. To test this concept we combined a dual-spinneret electrospinning set-up with a rotating plate as collector, in order to obtain a homogenous mixture of the two polymeric nanofiber types. The use of a similar strategy applied to aligned nanofiber meshes has previously been described [47], with the aim of overcoming the dense fiber packing and reduced pore size. It is known, however, that the random distribution of fibers is the most typical morphology of electrospun meshes, thus making the effective control of its pore size much more imperative. We propose herein the production of composite meshes of polycaprolactone (PCL) and poly(ethylene oxide) (PEO), with the posterior selective removal of the PEO fraction to control the pore size.

To determine the success of our approach, the characterization of the produced electrospun nanofiber meshes was performed by scanning electron microscopy (SEM), interferometric optical profilometry and contact angle tests, in order to determine the physical properties that may influence the cellular behavior. We also characterized the fiber diameter and pore size of the meshes by image analysis of SEM micrographs. Biologic assays were performed to show the efficacy of the processing method, facilitating cell penetration into the nanofiber meshes with increased pore size. A novel clamping system was developed to undoubtedly prove the cellular penetration through all the thickness of the produced meshes. The cultured cells were analyzed by SEM and laser scanning confocal microscopy. MTS and DNA assays were performed to determine the cell viability and proliferation. We conclude that the proposed method can be used to control the pore size without compromising the cell viability and proliferation. 


\section{Materials \& methods \\ Electrospinning processing}

Polycaprolactone, with a molecular weight of $80 \mathrm{kDa}$ (TONETM, Union Carbide Chemicals and Plastics Division, NJ, USA), was dissolved in an organic solvent mixture of chloroform (Sigma-Aldrich, MO, USA) and dimethylformamide (DMF; Sigma-Aldrich) in a 7:3 ratio at $17 \%(\mathrm{w} / \mathrm{v})$ concentration, as described elsewhere [48]. PEO (Sigma-Aldrich), with a molecular weight of $100 \mathrm{kDa}$, was dissolved at $25 \%$ $(\mathrm{w} / \mathrm{v})$ in a mixture of water and ethanol $(6: 4$ ratio). Both polymer concentrations and chloroform/DMF ratio were defined after several optimization stages to obtain the most stable processing, leading to the more convenient mesh morphology.

To produce the dual composition electrospun nanofiber meshes, a system was developed to allow the simultaneous electrospinning of more than one polymeric solution. Two independently controllable high voltage power supplies (semicommercial from UltraVolt, NY, USA, and Bosh, Germany) were used to generate electrical voltages ranging from 8 to $20 \mathrm{kV}$, with the lower values being applied to the PCL solution. Each polymer solution was placed in a $10 \mathrm{ml}$ syringe coupled to a $21 \mathrm{G}$ needle with a blunt tip. The feeding rate was established at a constant value of $0.25 \mathrm{ml} / \mathrm{h}$ by precision syringe pumps (Aladdin-1000-220B, UK) for both polymeric solutions.

A conducting and rotating plate, connected to the ground with a rotating speed of $15 \mathrm{rpm}$, was used as a collector to obtain a homogeneous nanofiber mixture. A collector to needle tip distance of $12 \mathrm{~cm}$ was defined after an optimization procedure and the syringes were placed at $9 \mathrm{~cm}$ distance to minimize the electrospun jet interference. The process was continued for at least $2 \mathrm{~h}$ for the production of each dual composition nanofiber mesh with a final thickness of $50-60 \mu \mathrm{m}$. The nanofiber meshes were further dried at room temperature for at least 1 day to remove all the remaining solvent.

With the goal of increasing the pore size of the dual composition nanofibers meshes, the PEO nanofibers were selectively removed by dissolution in distillated water for a period of $24 \mathrm{~h}$ at $37^{\circ} \mathrm{C}$. After the dissolution procedure the meshes were dried in an oven at $37^{\circ} \mathrm{C}$.

\section{Physical characterization}

The morphology of the electrospun nanofiber meshes was assessed by SEM (Leica Cambridge S360, UK). The meshes were sputter coated with gold (sputter coater model SC502, Fisons Instruments, UK) and then observed with an accelerating voltage of up to $15 \mathrm{kV}$. Samples were analyzed with the dual composition (PCL-PEO nanofiber mesh $[\mathrm{NFM}]$ ) and after the selective PEO dissolution (PCL-PEO NFM after PEO dissolution).

The fiber diameter was measured from SEM micrographs with the software ImageJ (version $1.38 \times$, Wayne Rasband National Institutes of Health, MD, USA). For each sample, at least ten micrographs were used (at $\times 5000$ magnification) and, in each micrograph, 15 different fibers were randomly selected. Pore size was also evaluated from SEM micrographs using the ImageJ software. The pore size values were obtained from SEM micrographs $(\times 5000$ magnification) in a total of 60 measurements for each condition. The pore size values were obtained by converting the contour of the pore area into a circumference of equivalent perimeter and determined from the circumference an equivalent diameter [49].

Interferometric optical profilometry was used to assess the topography of the samples. A surface profiler (DEKTAK3ST, Veeco, CA, USA) in vertical scanning interferometry (VSI) mode, with a vertical resolution of $3 \mathrm{~nm}$, was used to measure the surface roughness. Five different regions $(119 \times 91 \mu \mathrm{m})$ for each sample were measured. The average roughness and root mean square roughness values were automatically calculated by the equipment analytical software WycoVision $^{\circledR} 32$.

The wettability of the surfaces was assessed by contact angle measurements. Measurements of the static contact angle were carried out by the sessile drop method using contact angle equipment (model OCA 15plus, DataPhysics Instruments, Germany) with a high performance image processing system. The used standard polar liquid, water $(2 \mu \mathrm{l}$, HPLC grade) was added by a motor-driven syringe at different zones of each sample, and the measurement time was extended until $20 \mathrm{~min}$ at room temperature. At least three measurements were carried out for each sample (PCL NFM, PCL-PEO NFM and PCL-PEO NFM after PEO dissolution).

\section{Biologic assays}

The dual composition electrospun nanofiber meshes were cut into small disks with $8 \mathrm{~mm}$ diameter. In order to demonstrate the enhanced cellular infiltration into the nanofibers meshes, a system was developed to clamp the mesh. This system consisted of two silicone rings 
(with 8 and $5 \mathrm{~mm}$ of outer and inner diameter, respectively), held together with the sample in two points by a nylon stitch (FIGURe 1). When clamped between the rings, the samples have no direct contact with the surface of the well. This clamping system was sterilized by ethylene oxide, with the meshes already clamped between the rings.

A well-established cell line of human primary osteosarcoma ( $\mathrm{SaOs}-2$ cell line; European Collection of Cell Cultures [ECACC], UK) was utilized. Dulbecco's modified eagle medium (DMEM; Sigma-Aldrich) with 10\% fetal bovine serum (Biochrom AG, Germany) and $1 \%$ antibiotic-antimycotic mixture (Gibco, UK) was used to culture the cells. The cells were harvested by trypsinization before seeding onto the scaffolds.

Before seeding, the clamping systems containing the dual composition electrospun nanofiber meshes were placed in a 48-well plate with $1 \mathrm{ml}$ of ultra-pure water in order to dissolve the PEO nanofibers. The well plate was placed in an incubator at $37^{\circ} \mathrm{C}$ for a period of $24 \mathrm{~h}$. The seeding was performed with $50 \mu \mathrm{l}$ cell suspension $\left(1 \times 10^{5}\right.$ cells $\left./ \mathrm{ml}\right)$ over each scaffold. The developed nanofiber mesh clamping system confined the seeding area, avoiding cell adhesion to other surfaces of the culture well. The cell-seeded scaffolds were incubated in a humidified atmosphere at $37^{\circ} \mathrm{C}$, containing $5 \% \mathrm{CO}_{2}$, for $4 \mathrm{~h}$, following which $1 \mathrm{ml}$ of culture medium was added to each well. The culture medium was changed every 3-4 days. The experiment was performed in triplicate for every time culture period $(1,3$, 7 and 14 days).

To evaluate the cell morphology and their distribution in the nanofibrous scaffolds, the constructs were washed with phosphate buffer saline (PBS; Sigma) and fixed with $2.5 \%$ glutaraldehyde solution (Sigma). Then, they were dehydrated by immersion in a series of ethanol solutions with increasing concentration and airdried overnight in a hood. The samples were

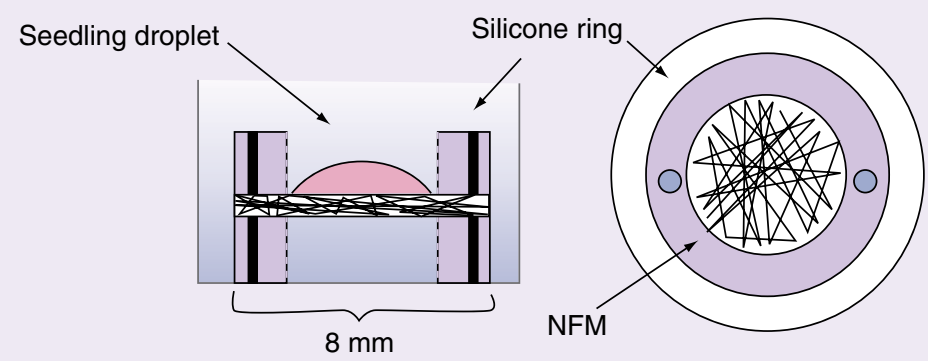

Figure 1. Clamping system used in the biologic assay. Lateral and top views NFM: Nanofiber mesh. sputter coated with gold (sputter coater model SC502, Fisons Instruments) and observed with SEM (Leica Cambridge S360, UK).

The penetration of the cells into the nanofiber mesh was evaluated by laser scanning confocal microscopy (Fluoview ${ }^{\mathrm{TM}}$ 1000, Olympus, Germany). The samples were fixed with formaline for $30 \mathrm{~min}$ at room temperature and then washed with PBS. The staining was performed with 4,6-diamidino-2-phenyindole dilactate (DAPI; Sigma) and phalloidin-tetramethylrhodamine B isothiocyanate (Sigma) for the nucleolus and actin filaments, respectively. The constructs were then mounted on glass microscope slides and observed. Samples were excited simultaneously at $345 \mathrm{~nm}$ for DAPI and $540 / 545 \mathrm{~nm}$ for phalloidin. Emission at $458 \mathrm{~nm}$ was mapped to the blue channel and $570 / 573 \mathrm{~nm}$ to the red channel. Nanofibers were observed in DIC black ground leveling mode. Representative images were taken as individual slices and the images are built from series of stacked images.

Cell viability was determined by the colorimetric MTS assay (CellTiter 96 ${ }^{\circledR}$ AqQueous One Solution Cell Proliferation Assay, Promega, WI, USA) on days 1, 3, 7 and 14 of culture. The constructs were immersed in phenol redand fetal bovine serum-free DMEM and the MTS reagent was added in a proportion of 5:1, in a total of $600 \mu \mathrm{l}$ per well. The well plate was incubated at $37^{\circ} \mathrm{C}$ for $3 \mathrm{~h}$, in accordance with the manufacturer instructions. Five replicas of $100 \mu \mathrm{l}$ were pipetted from each well and placed in a 96 Costar flat bottom well plate, and its absorbance read in a microplate reader (Synergie HT, Bio-Tek, USA) at $490 \mathrm{~nm}$.

Cell proliferation was assessed by the DNA quantification assay. This test determines the total amount of double-stranded DNA corresponding to different culturing time. Quantification was performed using the Quant-iT ${ }^{\mathrm{TM}}$ PicoGreen dsDNA Assay Kit (Invitrogen $^{\mathrm{TM}}$, Molecular Probes ${ }^{\mathrm{TM}}$; OR, USA). Briefly, cells in the construct were lysed by osmotic and thermal shock and the supernatant used for the DNA quantification assay. A fluorescent dye, PicoGreen, was used owing to its high sensitivity and specificity to double-stranded DNA. The fluorescence of the dye was measured at an excitation wavelength of $485 / 20 \mathrm{~nm}$ and at an emission wavelength of 528/20 nm, in a microplate reader (Synergie HT, Bio-Tek, USA), with the intensity of the signal proportional to the amount of DNA. Triplicates were made for each sample, thus allowing a statistical 

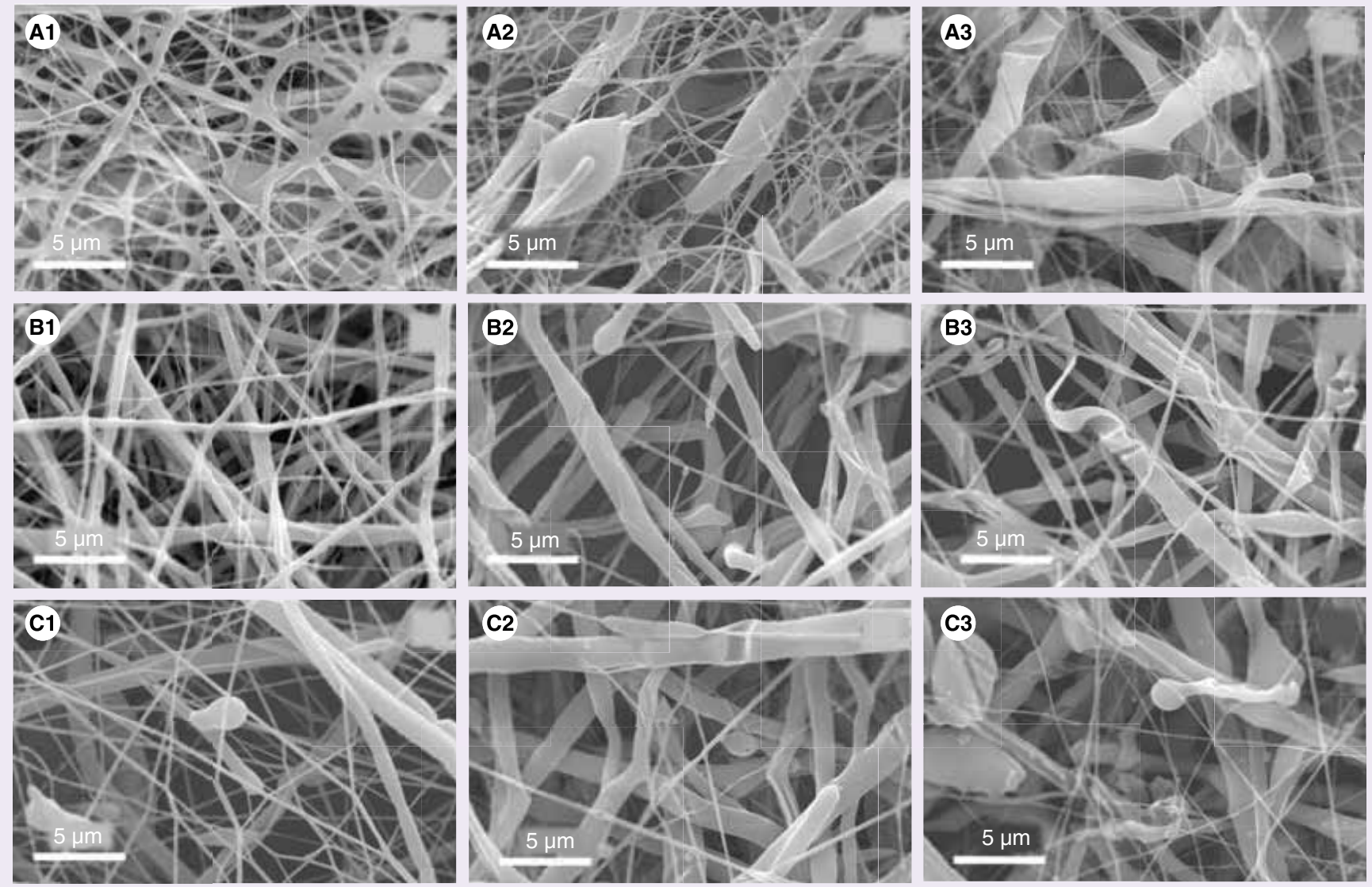

Figure 2. Scanning electron micrographs of electrospun dual composition polycaprolactone-poly(ethylene oxide) nanofiber mesh, produced with different applied tensions, from lower (A) to higher (C), without dissolution (1), after $2 \mathrm{~h}$ (2) and $24 \mathrm{~h}$ of dissolution (3) at $37^{\circ} \mathrm{C}$. Original $\times 500$ magnification.

analysis to be performed. The DNA concentration of each sample was calculated using a standard curve relating the quantity of DNA with fluorescence intensity.

\section{Statistical analysis}

Statistical analysis was performed using the SPSS statistic software (Release 8.0.0 for Windows). First, a Shapiro-Wilk test was performed to determine the data normality. This test showed that some results do not follow a normal distribution. In the analysis of the results, p-values lower than 0.01 were considered statistically significant.

To compare the morphological properties (i.e., fiber diameter, pore size, roughness parameters and water contact angle) of the produced NFMs, a Kruskal-Wallis test was performed. When the analysis indicated significant differences among the produced NFMs, Tukey's honestly significant difference (HSD) test for multiple comparisons was performed to find where the differences occur. In the case of biological results, which also did not follow a normal distribution, a Mann-Whitney U-test was performed to determine the cell performance when cultured in those NFMs.

\section{Results}

Initially, PCL and PEO solutions were individually electrospun under several solution parameters (polymer and solvent concentration) as well as processing parameters (voltage, needle tip to collector distance and flow rate) in order to produce homogeneous fibers with uniform diameters in the absence of visible defects, namely beadlike morphology. Both polymers were electrospun with a needle tip to collector distance of $12 \mathrm{~cm}$ and voltages in the range of $9-15 \mathrm{kV}$ for PCL solution and 13-19 kV for PEO solution. Due to the process instability caused by the relative proximity of the two electrically driven polymer jets, the applied voltages for both polymers was varied, although always with a higher voltage for the PEO solution. Lower applied voltages were observed to result in fibers with visible defects and also regions of polymer aggregation (Figure 2, A2). Higher applied voltages produced less uniform 
fibers with larger diameter variations on the same fiber mesh (Figure 2, C1). Smooth, uniform fibers without bead-like structures were observed using intermediate voltages (Figure 2, B1). This sample was processed at $15 \mathrm{kV}$ for PCL solution and $17 \mathrm{kV}$ for PEO solution. The dual composition PCL-PEO NFM used afterwards were all processed using these optimal processing conditions.

To determine the ideal dissolution conditions for PEO nanofibers, several electrospun dual composition PCL-PEO NFM were immersed in distilled water without mechanical agitation. It was described in the literature that the PEO dissolution kinetics in water increases in the temperature range $20-40^{\circ} \mathrm{C}$ [50]. Thus, a distilled water bath was heated at $37^{\circ} \mathrm{C}$ to attain conditions promoting a faster and complete dissolution of the PEO fraction. After a dissolution period of either 2 or $24 \mathrm{~h}$, the meshes processed at lower voltages showed a beaded morphology with significant variation in fiber diameter and polymer accumulation (Figure 2, A2 \& A3). After PEO dissolution of $24 \mathrm{~h}$, the nanofibers maintained their continuity and general morphology in meshes processed at intermediate voltage. The PCL nanofibers, after the dissolution of the PEO fraction, assumed a twisted morphology (Figure 2, B3). The final morphology of the mesh obtained with higher voltage shows discontinuous fibers with abrupt variations of the fiber diameter and polymer accumulation points (Figure 2, C3). All samples presented visible surface marks caused by the dissolution of PEO fibers (Figure 2, A3, B3 \& C3). The SEM micrographs showed that PCL-PEO meshes, when submitted to the dissolution process for $24 \mathrm{~h}$, have an enhanced pore size caused by the dissolution of the PEO fraction. All subsequent dissolutions were preformed during a period of $24 \mathrm{~h}$ at $37^{\circ} \mathrm{C}$. Meshes were randomly selected for posterior characterization assays.

\section{- Physical characterization}

The PCL and PEO solutions were simultaneously processed by electrospinning, resulting in a 3D dual composition nanofibrous structure with interconnected micropores, composed of uniform and randomly oriented nanofibers (Figure 3B). Applying the Kruskal-Wallis test to the fiber diameter results, we found a highly significant difference between the produced NFMs $(\mathrm{p}<0.0001)$. Tukey's HSD test indicated that the fiber diameter distribution in PCL-PEO NFM after PEO dissolution is comparable with that observed for the control PCL NFM $(\mathrm{p}=0.183)$ (Figure 4). It was noticed that the PCL-PEO NFM submitted to the dissolution process showed a marginal increase in the average fiber diameter $(\sim 157 \mathrm{~nm})$, which did not significantly affect the fiber diameter distribution when compared with the control PCL NFM.

Comparing the SEM micrographs of control PCL NFM (Figure 3A) and dual composition PCL-PEO NFM (Figure 3B) with the PCL-PEO
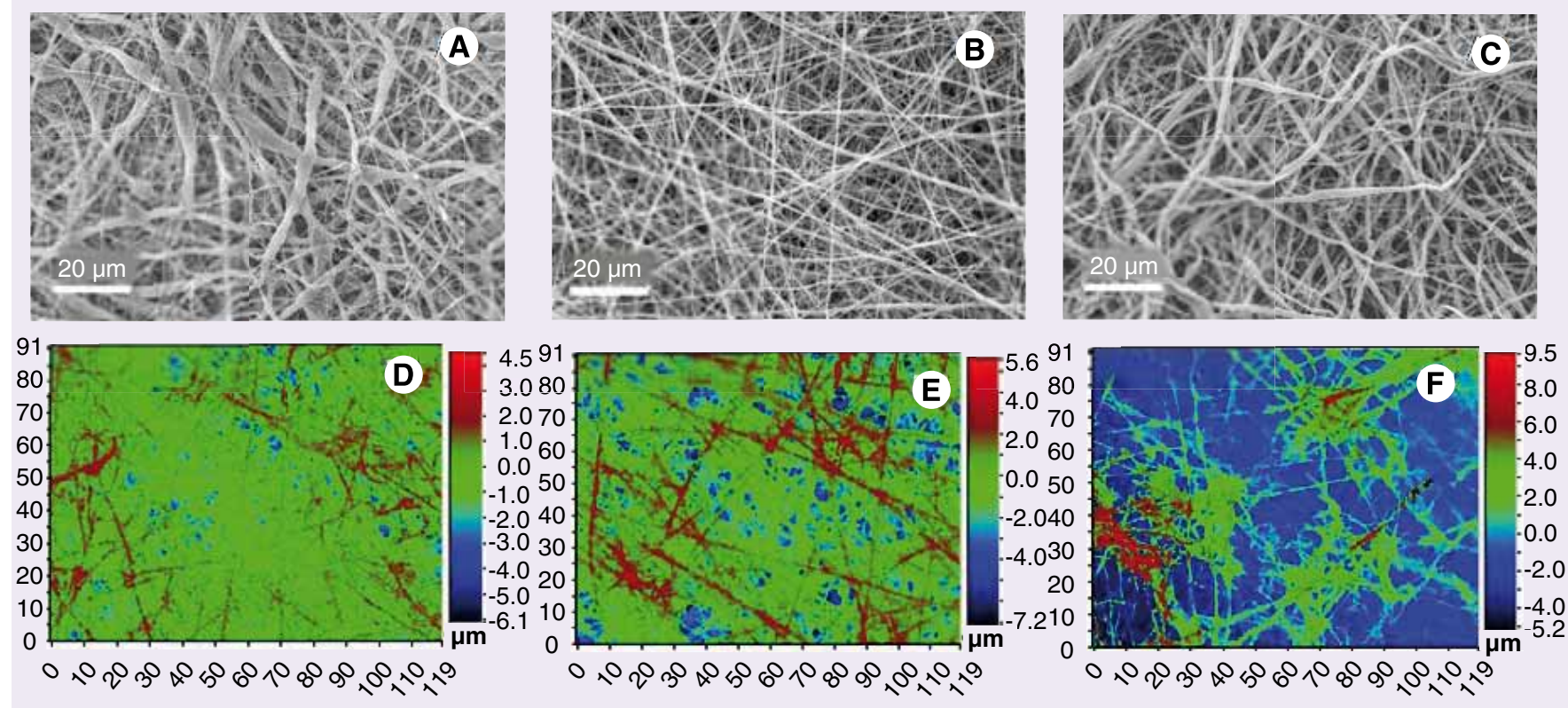

Figure 3. Scanning electron micrographs (A-C) and interferometric optical profilometry images (D-F) of electrospun control PCL NFM (D), dual composition PCL-PEO NFM (E) and PCL-PEO NFM after PEO dissolution (F). Original magnification of $\times 1000$ and $\times 518$, respectively.

NFM: Nanofiber mesh; PCL: Polycaprolactone; PEO: Poly(ethylene oxide). 
NFM after PEO dissolution (Figure 3C), an apparent increment was observed in the size of the pores, accommpanied by a decrease in the number of pores. Indeed, the PCL-PEO NFM after PEO dissolution had statistically significant larger pores $(\mathrm{p}<0.001)$, as revealed by Tukey's HSD test (Figure 5). Interferometric optical profilometry images confirmed the pore size increment in the samples and consequent topographical alterations. The higher in-depth scale of the PCL-PEO NFM after PEO dissolution could be indicative of a more open structure and presence of loosely connected fibers in this sample (Figure 3F). An increment of the pore size was also confirmed by the significant higher average roughness of the PCL-PEO NFM after PEO dissolution ( $\mathrm{p}=0.001)$ (Figure 6 ), determined by interferometric optical profilometry. Essentially, both SEM and interferometric optical profilometry show consistent results with the increased level of pore size when performing PEO fiber dissolution.

To ascertain the influence of these topographical alterations over the hydrophobic/ hydrophilic character of the samples, the water contact angle evolution over a period of $20 \mathrm{~min}$ was measured for control PCL NFM, dual composition PCL-PEO NFM and PCL-PEO NFM after PEO dissolution (Figure 7). Generally, all samples show a hydrophobic character. However, the dissolution of PEO induced a statistically significant reduction of the water contact angle ( $p<0.001)$, as revealed by Tukey's HSD test, until 16 min of wettability. There were no statistically significant differences in the water contact angle between the control PCL NFM and the dual composition PCL-PEO NFM ( $p=0.07)$. At $18 \mathrm{~min}$, the only statistically significant difference was observed in the wettability between the dual composition PCL-PEO NFM and the PCL-PEO NFM after PEO dissolution $(p<0.01)$. Moreover, at 20 min no statistically significant differences in the wettability between the three types of NFMs existed ( $p>0.01)$.

\section{Biologic characterization}

The adhesion, spreading, viability and proliferation of human osteoblastic cells on the dual composition electropun nanofiber meshes after PEO dissolution were evaluated for 1, 3, 7 and 14 days of culture (PCL NFM were include as controls). Figure 8 shows SEM micrographs of cultured cells on the electrospun meshes. In the case of the control PCL NFM, the adhesion only happens at the surface of the nanofiber mesh (Figure 8A). Cell infiltration into the mesh

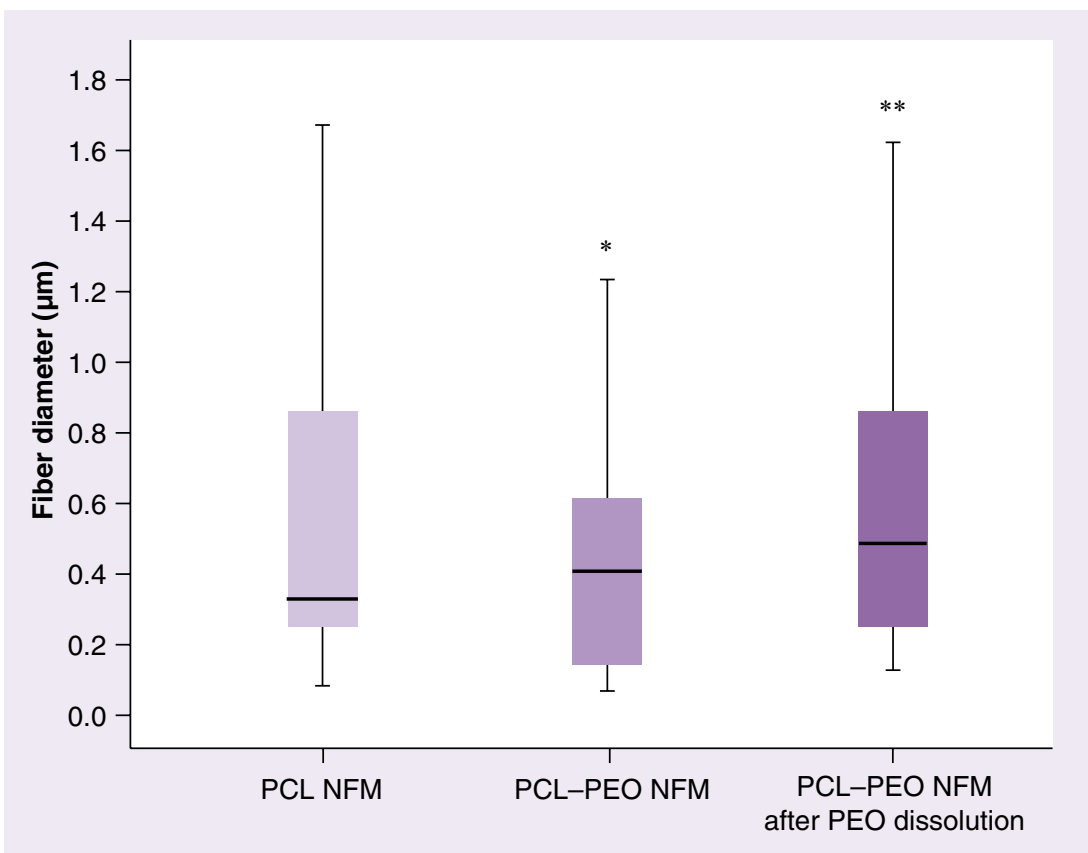

Figure 4. Box plot of fiber diameter for control PCL NFM, dual composition PCL-PEO NFM and PCL-PEO NFM after dissolution.

${ }^{*} p<0.01$ versus control PCL NFM.

${ }^{\star *} \mathrm{p}<0.01$ versus PCL-PEO NFM.

NFM: Nanofiber mesh; PCL: Polycaprolactone; PEO: Poly(ethylene oxide).

is observed on PCL-PEO NFM after PEO dissolution for longer culture periods (Figure 8, B3). Cells are visible in different layers of the NFM, below the upper level of the nanofibers and

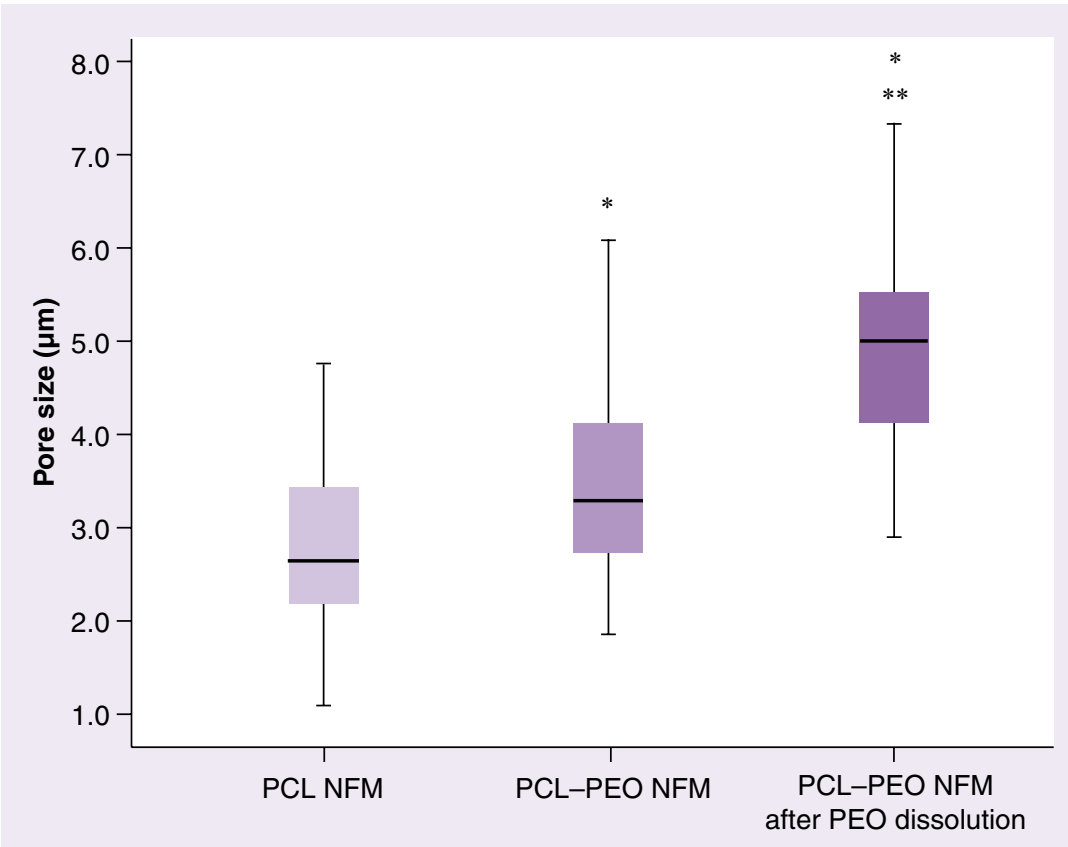

Figure 5. Box plot of pore size on control PCL NFM, dual composition PCL-PEO NFM and PCL-PEO NFM after dissolution.

${ }^{*} p<0.01$ versus control PCL NFM.

${ }^{* *} p<0.01$ versus PCL-PEO NFM.

NFM: Nanofiber mesh; PCL: Polycaprolactone; PEO: Poly(ethylene oxide). 


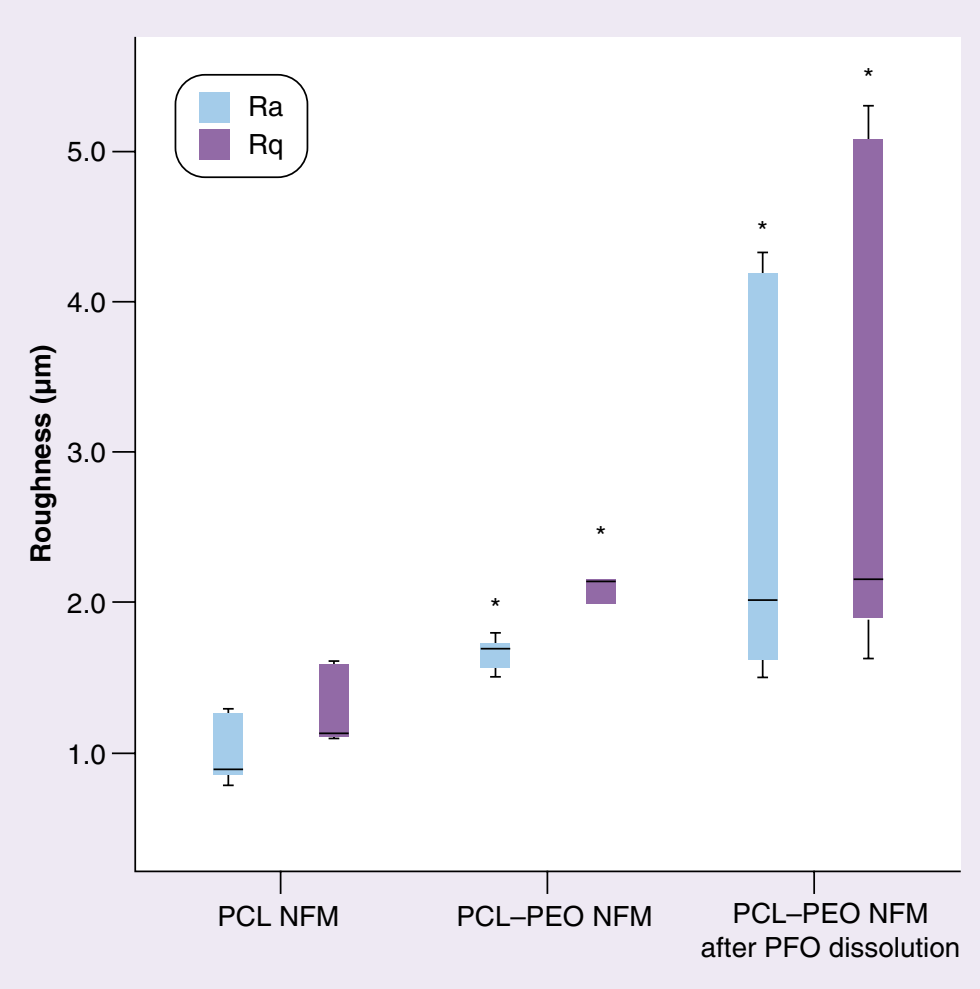

Figure 6. Box plot of roughness parameters, namely average roughness and root mean square roughness, on control PCL NFM, dual composition PCL-PEO NFM and PCL-PEO NFM after dissolution.

${ }^{*} \mathrm{p}<0.01$ versus control PCL NFM.

NFM: Nanofiber mesh; PCL: Polycaprolactone; PEO: Poly(ethylene oxide);

Ra: Average roughness; Rq: Root mean square roughness.

inside the mesh structure (Figure 8, B3 \& B4). After 14 days of culture, both samples have their top surface (seeding surface) almost fully covered with cells. Furthermore, in control PCL NFM a confluent cell layer was observed, which was not previously seen in the dual composition meshes.

To further confirm cell penetration into the nanofiber meshes, the opposite side of the seeding surface of the meshes was also observed by SEM (FIgure 8C). As the seeding was performed in the area confined by the clamping silicone ring, the cells present in the opposite surface of the mesh could only migrate through the thickness of the nanofiber mesh. This result shows that the increased pore size and the overall morphology of the PCL-PEO after PEO dissolution allows cell penetration into the mesh. For longer culture periods, an increment in the cell number at the surface of the nanofiber mesh was observed. On this side of the mesh, a progressive infiltration of the cells was visible from the interior of the mesh to its surface (FIgure 8D). In control PCL NFM this infiltration was not observed and the cells were absent at the opposite side of the mesh (Figure 8C), demonstrating the efficiency of the ring system in confining the cell adhesion.
Detailed and further magnified micrographs illustrate cellular infiltration into the PCL-PEO NFM after PEO dissolution (Figure 8E). SEM micrographs show a progressive cell penetration during the culture periods. Cells were visible underneath several fibers and in different layers across the mesh thickness (Figure 8, E3 \& E4).

To further confirm the cellular penetration observed in SEM, laser scanning confocal microscopy was conducted on control PCL NFM and PCL-PEO NFM after PEO dissolution cultured with human osteoblastic cells (Figures 9 \& 10). Cells appeared rounded and uniformly distributed over the scaffold surfaces after 1 day (Figures 9A \& 10A). For longer culture periods (7 days), control PCL NFM still contained cells mainly at the surface of the mesh (Figure 9B). By contrast, in PCL-PEO NFM after PEO dissolution, cells appeared spread and were detected in the inner/deeper layers of the NFM (Figure 10), colonizing the full thickness of the scaffold and infiltrating into the unseeded side of the mesh. These observations are thus in agreement with the results from the SEM analysis.

The viability of the osteoblastic cells cultured on the control PCL NFMs and on the PCL-PEO NFM after PEO dissolution was assessed by MTS assay (Figure 11). Cell viability was significantly higher on the PCL-PEO NFM after PEO dissolution ( $p<0.001$ ), as revealed by the Mann-Whitney U-test, for almost all the time points. The only exception was the time point 7 days, where no significant differences were found between both NFMs ( $p=0.063$ ). The higher viability of cells seeded on the PCL-PEO NFM after PEO dissolution can be justified by the attachment and growth of cells into the open structure of the mesh. Furthermore, a progressive increment of cell viability along with culturing time was also observed for both nanofiber meshes.

Cellular proliferation was estimated based on the DNA quantification assay (Figure 12). In control PCL NFM, the DNA content increased slightly until 3 days of culture, where it reached the maximum value, after which time it reduced from that time point onwards. In PCL-PEO NFM after PEO dissolution a statistically significant decrease in DNA content was observed at day 3 ( $\mathrm{p}=0.002)$, followed by a progressive increment for longer culture periods. Despite this progressive increment of DNA quantity, no statistically significant difference was found between PCL-PEO NFM after PEO dissolution and the control PCL NFM ( $p>0.01)$, as revealed by the Mann-Whitney U-test. 


\section{Discussion}

In natural tissues the cells are surrounded by the ECM, which provides structural support for the cells, controls the tissue structure and regulates cell adhesion, migration, proliferation and, consequently, tissue morphogenesis. The ECM is a dynamic and hierarchal organized structure composed of polysaccharides (glycosaminoglycans) and proteins (collagen and proteoglycans). These components are organized as an interconnected nano- or micro-ranged fibrous network [17]. In the past two decades, nanofiber meshes produced by electrospinning have been described as having a large potential in the field of tissue regeneration $[17,40,51]$. Electrospun meshes closely resemble the ECM due to their nanoscale structure and can act as a functional replacement of the ECM [17,51]. The most serious limitation on the use of the nanofiber meshes as tissue engineering scaffolds in 3D tissues is most likely the fact that the pores created by the random deposition of nanofibers are too small to allow cell infiltration into the inner regions of the nanofiber mesh $[17,23,51]$. Most of the reports in literature using electrospinning to produce tissue templates do not provide any strategy to overcome this problem, compromising the scaffold's effectiveness for the proposed applications.

We propose the electrospinning of a dual composition nanofibrous structure that is intentionally designed for cell penetration, obtained by the selective extraction of one material of the nanofiber mesh. This strategy would create larger pores that could promote cell infiltration to the inner region of the mesh and, at same time, maintain the structural and biological properties that resemble the ECM structure. Unlike some previously described strategies to increase pore size, such as techniques that use blowing agents [45] or postprocessing by laser [46], our strategy modifies the nanofiber mesh as a whole, providing an homogeneous pore size distribution. The developed system allows an independent voltage control, since the PCL and PEO solutions have different properties and, consequently, need to be processed at different conditions. In addition, the proposed postprocessing technique is very simple and does not involve any extra component that could eventually compromise cellular behavior.

It is hypothesized that the PEO dissolution products are nontoxic and will not be detrimental for cell viability. In fact, the dissolution of

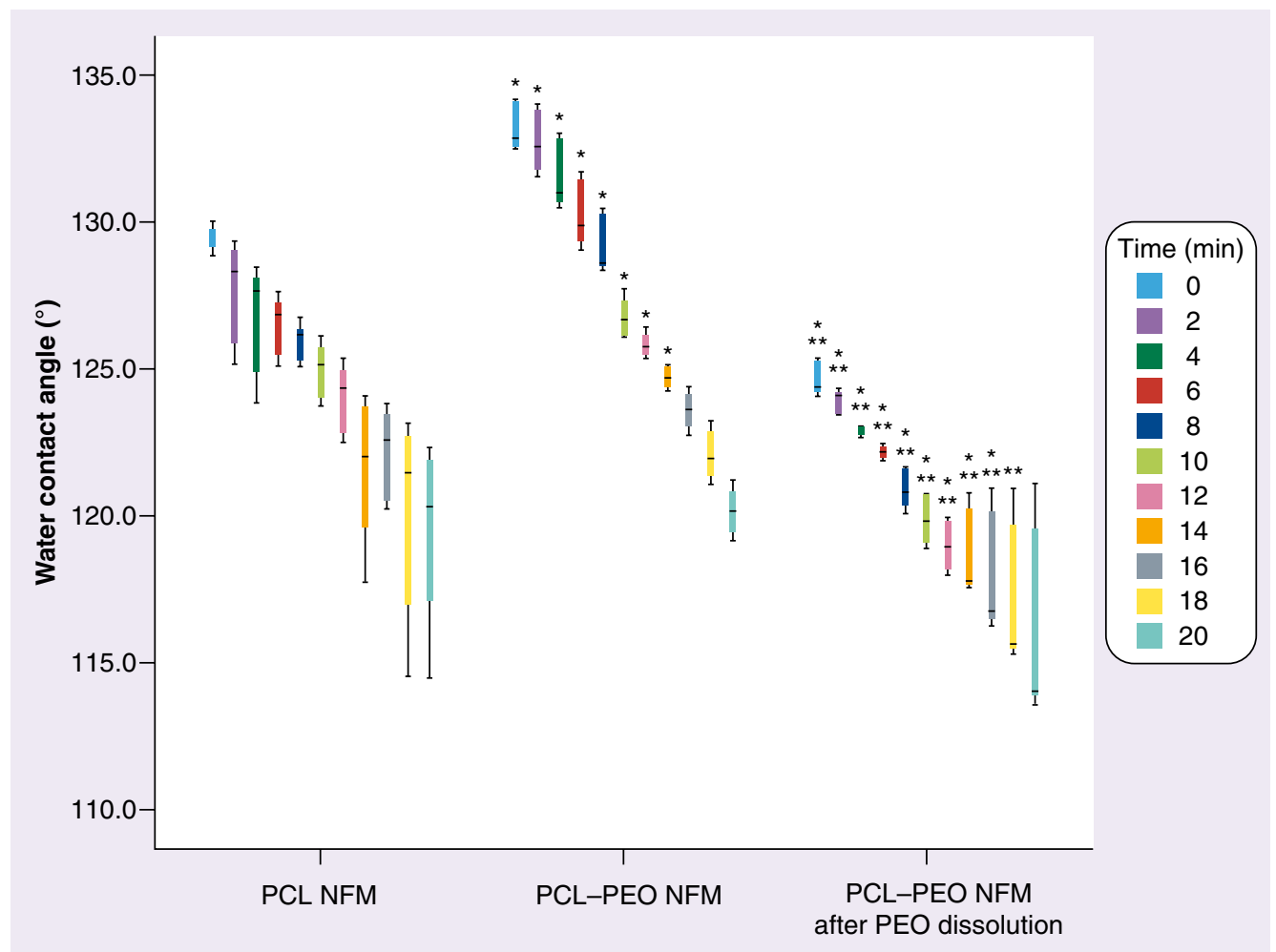

Figure 7. Box plot of water contact angle values for control PCL NFM, dual composition PCL-PEO NFM and PCL-PEO NFM after PEO dissolution NFM, as a function of time.

${ }^{*} p<0.01$ versus control PCL NFM.

${ }^{* *} \mathrm{p}<0.01$ versus $\mathrm{PCL}-\mathrm{PEO}$ NFM.

NFM: Nanofiber mesh; PCL: Polycaprolactone; PEO: Poly(ethylene oxide). 

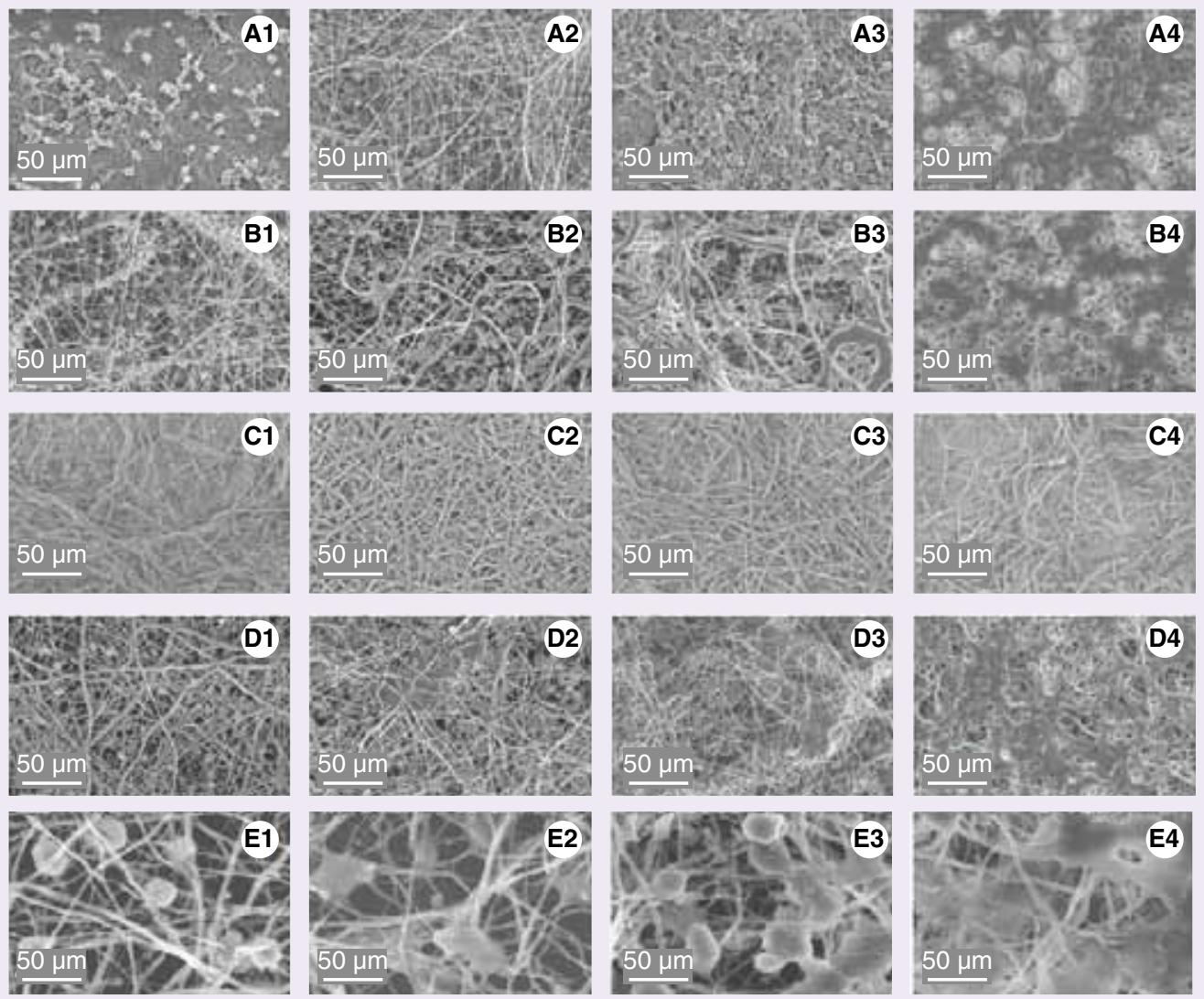

Figure 8. Scanning electron micrographs of electrospun control PCL NFM (A) and PCL-PEO NFM after PEO dissolution (B), and opposite face of control PCL NFM (C) and PCL-PEO NFM after PEO dissolution (D) cultured with human osteoblastic cells during 1 (1), 3 (2), 7 (3) and 14 days (4). Original magnification of $\times 500$. (E) Details of cellular infiltration on PCL-PEO NFM after PEO dissolution. Original magnification of $\times 2200$.

NFM: Nanofiber mesh; PCL: Polycaprolactone; PEO: Poly(ethylene oxide).

PEO nanofibers in water has revealed itself as an efficient method to obtain the selective removal. This was verified by the 'fingerprinting' marks of PEO nanofibers visible on the remaining PCL fibers, constituting an important characteristic of the obtained meshes. Those marks result from the deposition of the fibers in the collector being not completely dry and are caused by the overlap of PEO and PCL fibers. According to previous experimental results from the literature, the solubility of $\mathrm{PEO}$ in water increases in the temperature range of $20-40^{\circ} \mathrm{C}$ and tends to saturate at higher temperatures [50]. Thus, the PEO dissolution was performed at the temperature of $37^{\circ} \mathrm{C}$, the same temperature at which the biologic assays are conducted, ensuring that the PEO was successfully and completely removed at that temperature. This temperature is lower than the melt temperature of both polymers, which does not involve nanofiber morphology alterations during the process of dissolution. Due to the presence of impurities in the PEO solution, some aggregates of PEO were also observed and produced during the dissolution in water [50], which may cause morphologic alterations in the nanofiber mesh. Considering the hydrophobic character of PCL, no significant morphological alterations are expected within the PCL nanofibers. To confirm this statement, different topographical properties of the electrospun meshes, namely fiber diameter, pore size and roughness, were characterized. Fiber diameter measurements show that most of the produced fibers have diameters in the range of $175-875 \mathrm{~nm}$, thus in the submicrometric range. Considering the main aim of the present study, it is not advantageous to have very small fiber diameters, since increasing fiber diameter results in an increase in the mean pore size, as previously discussed [42]. Hypothetically, the slightly higher, but not statistically significant, diameter of the fibers measured in the PCL-PEO NFM after PEO dissolution may also contribute to a larger pore size in these meshes. Even so, the electrospun nanofiber meshes have a maximum probability of being effective in mimicking the natural ECM and allowing cell infiltration. 
Different methods have been proposed in the literature to measure the pore size and degree of porosity. Sieving methods [52], mercury intrusion porosimetry [53,54] and flow porosimetry [54] are among the most used methods to determine pore size. In the present study, the evaluation of pore size was performed by quantitative image analysis of SEM micrographs [55]. As expected, PCL-PEO
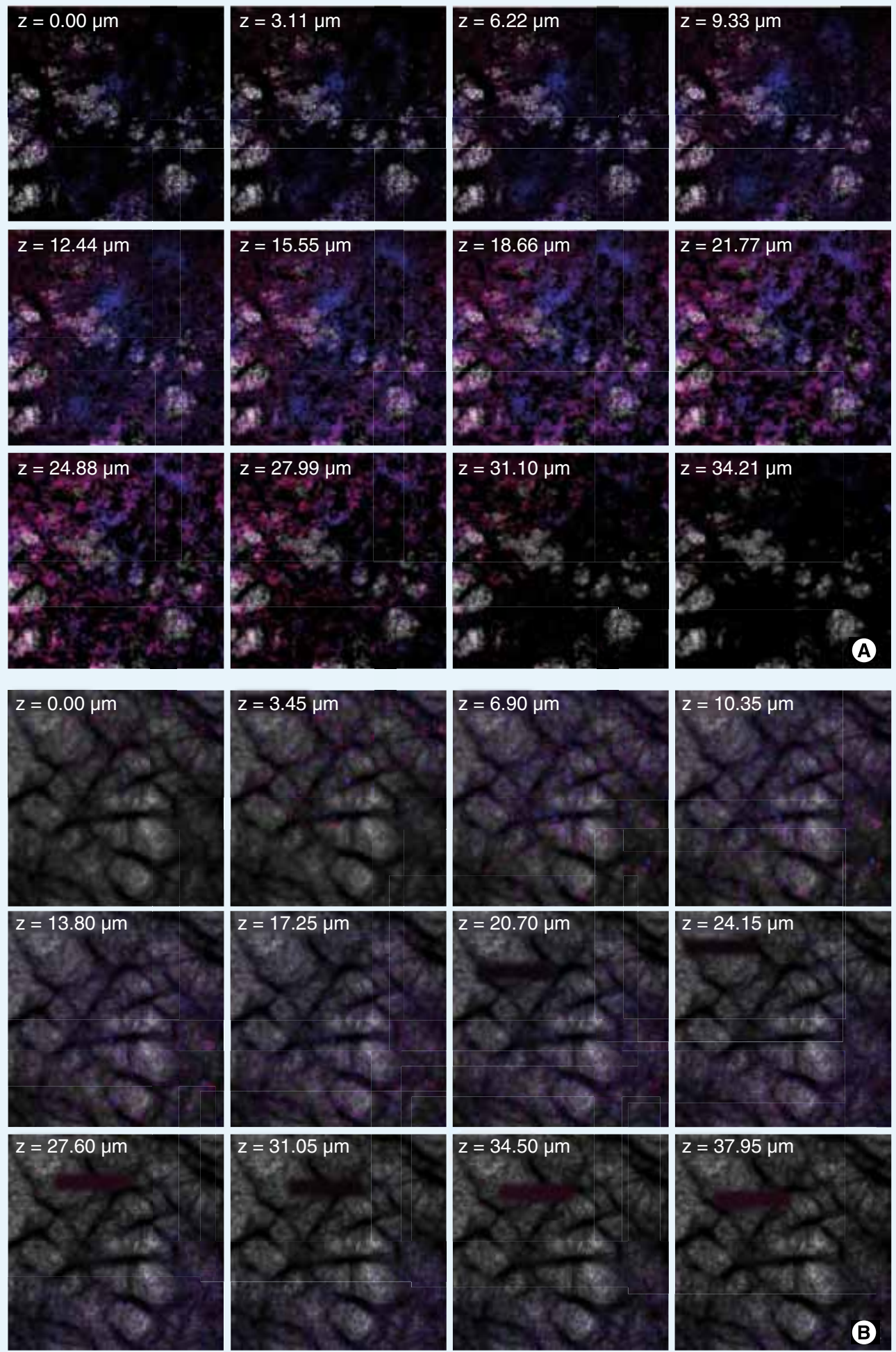

Figure 9. Laser scanning confocal microscopy images of electrospun control polycaprolactone nanofiber mesh after 1 (A) and 7 days (B) of human osteoblastic cells culture. Cell nuclei were stained with 4,6-diamidino-2-phenyindole dilactate and actin filaments stainded with phalloidine. Original magnification of $\times 10$. 
NFM after PEO dissolution had the largest pore sizes. The dissolution of PEO fibers results in pore sizes significantly higher than similar PCL meshes, which is in agreement with the removal of half of the fibers that constitute the mesh. The enhanced pore size meshes present a median pore
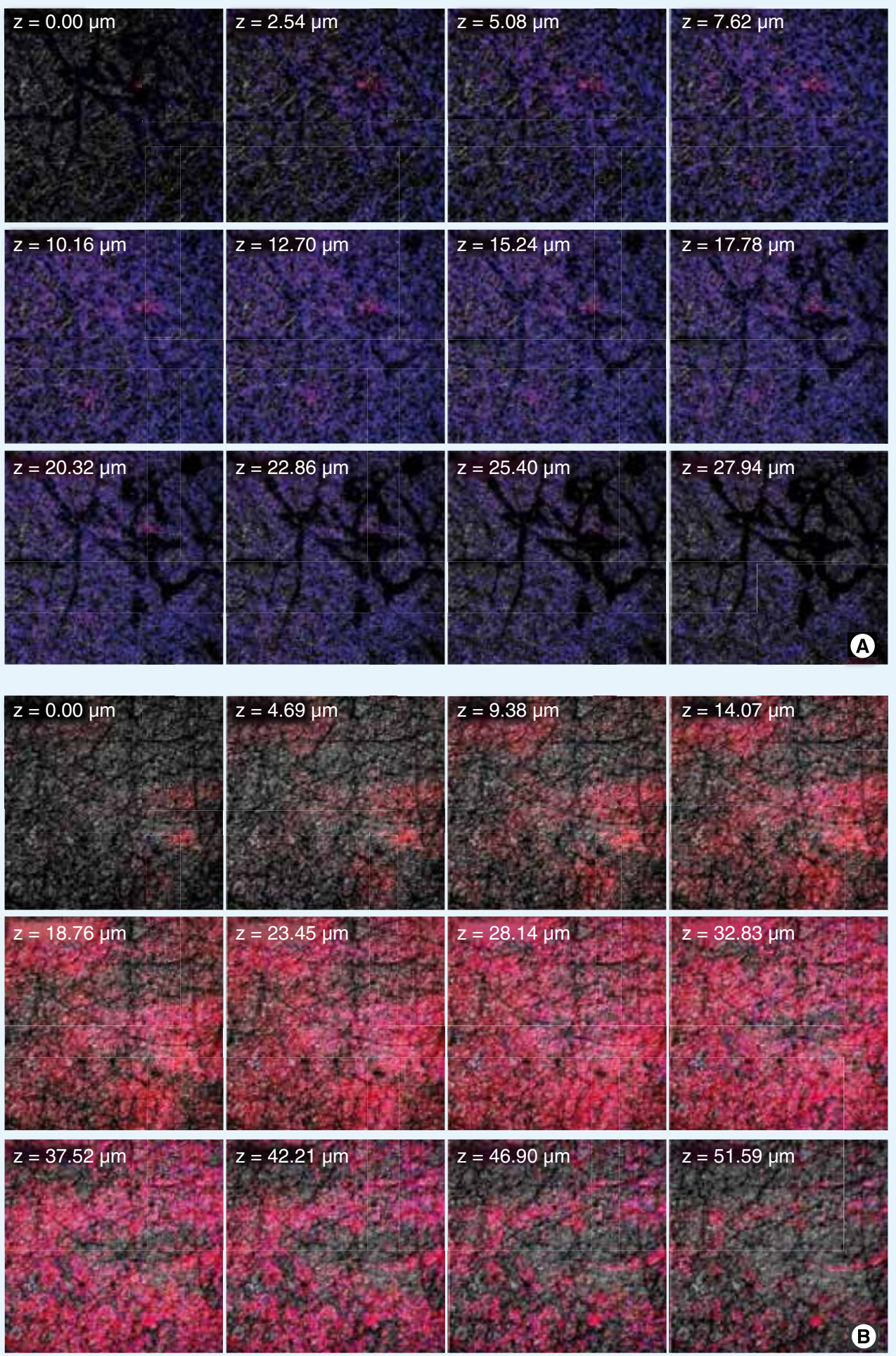

Figure 10. Laser scanning confocal microscopy images of PCL-PEO NFM after PEO

dissolution, after 1 (A) and 7 days (B) of human osteoblastic cells culture. Cell nuclei were stained with 4,6-diamidino-2-phenyindole dilactate and actin filaments stainded with phalloidine. Original magnification of $\times 10$.

NFM: Nanofiber mesh; PCL: Polycaprolactone; PEO: Poly(ethylene oxide). 
diameter of $5.017 \mu \mathrm{m}$. This is in the same range of values as previously reported by Tzezana et al. [55]. The PCL-PEO NFM after PEO removal clearly showed larger pores, as depicted by the interferometric optical profilometry images. These meshes also present larger topography gradients between the top and bottom fibers, which can be an indication of a more open mesh structure and of the presence of loosely connected nanofibers. Considering this higher distance and the fact that the fibers are slightly larger, it is consistent with a considerably higher average roughness of those samples, being the roughest of all three samples analyzed by this technique.

These differences in roughness could have also influenced the hydrophobic/hydrophilic character of the samples and, consequently, the cell behavior [56]. The contact angle assay showed a decrease of the hydrophobicity of the PCL-PEO NFM after PEO dissolution, when comparing with control PCL NFM. Despite the maintenance of a hydrophobic character, the PEO dissolution turned the PCL-PEO NFM into a more hydrophilic structure. This effect can be related to the increased fiber diameter of the dual composition PCL-PEO NFM. As reported in the literature, the increase in the fiber diameter causes a decrease in the water contact angle [56]. In addition, it has been shown that smaller pore sizes lead to higher air entrapment in the pore structure, which may cause an increase in water contact angle [56]. This is particularly evident on control PCL NFM. Conversely, higher pore size induced a decrement on water contact angle, as shown in our results.

The biological performance of the PCL-PEO NFM followed by PEO dissolution was assessed by the cellular infiltration level, cell viability and proliferation into the inner regions of the produced nanofibrous meshes. To demonstrate that human osteoblastic cells could migrate through the thickness of the NFM, a special clamping system was developed. This system was designed to have the double function of limiting the seeding area and to clamp the meshes at a certain distance from the bottom of the culture well plate. Thus, while in control PCL NFM the cell infiltration is limited to the top surface of the nanofiber mesh (because the pore size is insufficient to allow infiltration), in the PCL-PEO NFM after PEO dissolution, the infiltration of the cells into the inner regions of the mesh was observed, mainly for longer culture periods. In these meshes, the cells are clearly visible at various depths within the nanofiber mesh and covering different levels of the mesh, as confirmed by

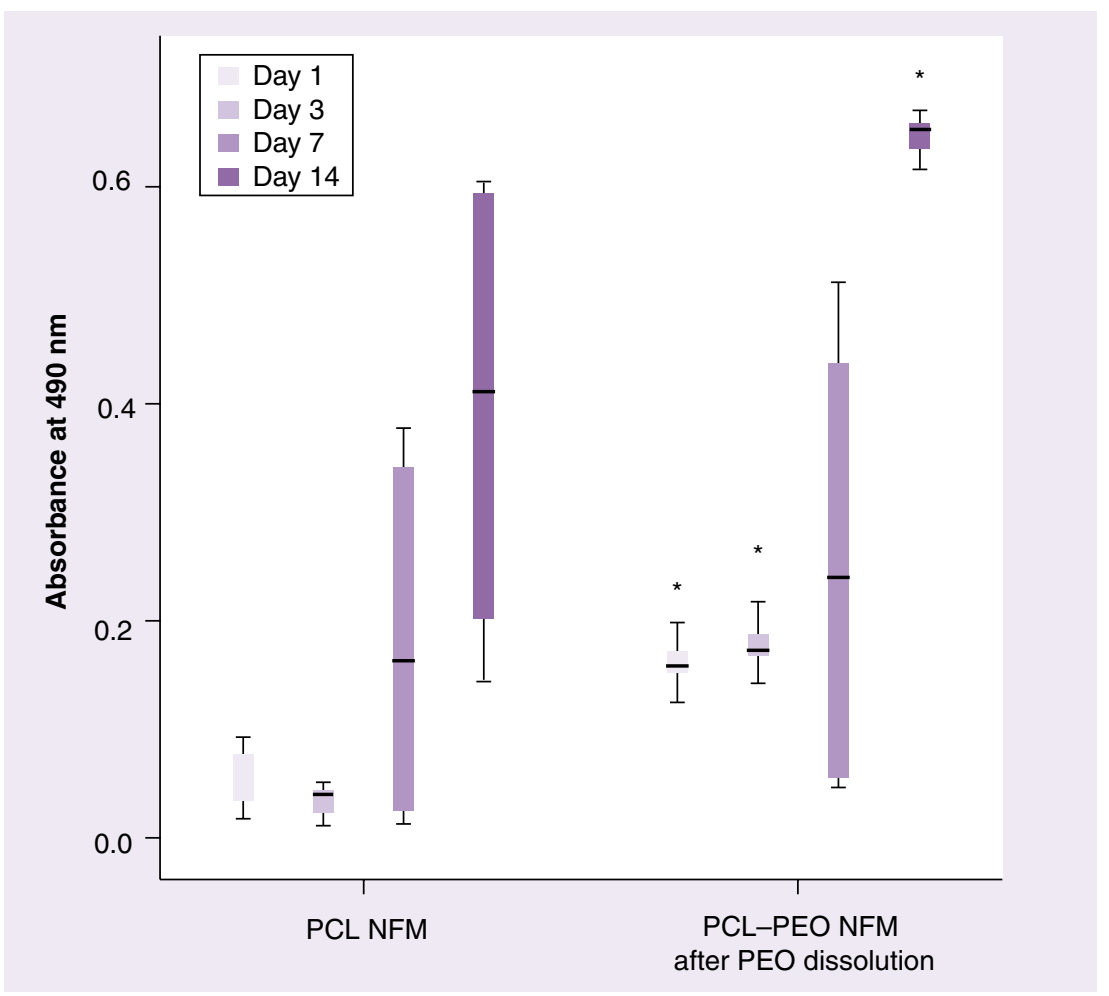

Figure 11. Box plot of human osteoblastic cells' viability cultured on control PCL NFM and PCL-PEO NFM after PEO dissolution.

${ }^{*} p<0.01$ versus control PCL NFM.

NFM: Nanofiber mesh; PCL: Polycaprolactone; PEO: Poly(ethylene oxide).

laser scanning confocal microscopy. The extent of cell infiltration was also evaluated by SEM observation of the opposite face of the mesh that was not seeded with cells. The presence of cells in this surface was observed only in the PCL-PEO NFM after PEO dissolution. In fact, in the initial days of culturing, the cells are seen inside the mesh, progressing along the culturing period and reaching the opposite surface of the mesh. Conversely, control PCL NFM shows no cells in the opposite side of the mesh even for long culturing periods. This result demonstrates that the presence of cells in the opposite surface of the PCL-PEO NFM after PEO dissolution is in fact due to cell infiltration through the mesh thickness and not due to any other cell colonization alternative. The previously published work on dual-polymer composite fiber-aligned scaffolds [47] did not report results showing an even distribution of cells through the scaffold thickness. Our results demonstrate unequivocally that the obtained pore size and porosity are sufficient to allow extensive cell infiltration from one side of the mesh to the other.

The enlargement of the pore size may facilitate the cell penetration in the dual composition meshes. However, this result may also be related to the loosely connected structure of electrospun 
meshes that are formed by differently oriented fibers lying without physical connection with the neighboring fibers (caused by the dissolution of the PEO fibers). The removal of the PEO fibers may also lead to discontinuities in the remaining PCL fibers. In this way, the surrounding fibers will offer only a minor resistance to the migration of cells [57]. It is remarkable that the biological results herein reported are obtained using a shorter culturing period (14 days) and cells with lower migratory capabilities, when comparing with mesenchymal stem cells used in other work [47]. Furthermore, our results show infiltration of cells through the full thickness of the nanofiber mesh. Other work following a similar strategy only reported a gradient of cells from the edge ( $\sim 45 \%$ of cells remain in the outer quarter) to the center of the construct $(\sim 12 \%$ of total cell population reach the center region).

The viability of cultured cells was assessed by the MTS test and significantly improved cell viability was found within the PCL-PEO after PEO dissolution when compared with control PCL NFM. The extra access to the inner mesh structure facilitates the attachment of cells and allows further cell penetration. The progressive increase in cell viability also demonstrates that

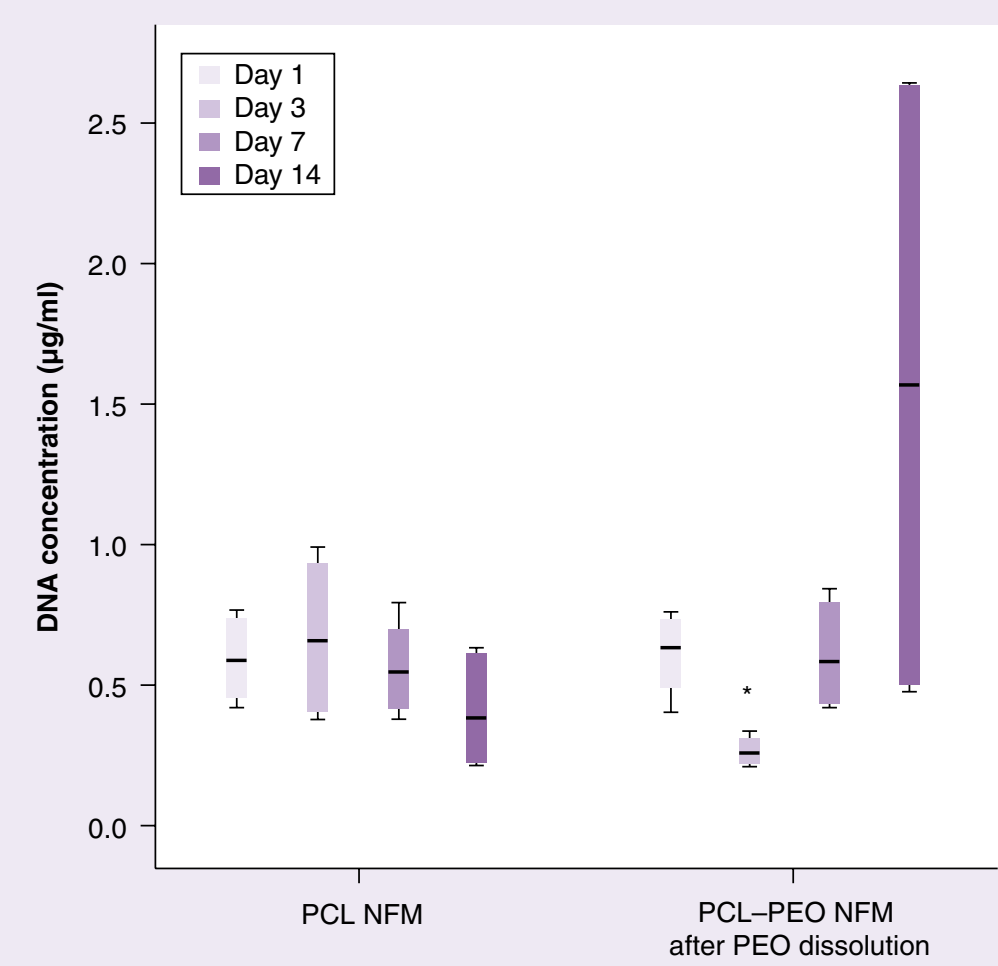

Figure 12. Box plot of cell proliferation on control PCL NFM and PCL-PEO NFM after PEO dissolution, estimated according to the DNA quantification assay.

${ }^{*} \mathrm{p}<0.01$ versus control PCL NFM.

NFM: Nanofiber mesh; PCL: Polycaprolactone; PEO: Poly(ethylene oxide).
PEO dissolution, along with PEO dissolution products, do not negatively affect the cell viability. Furthermore, the cellular proliferation assay shows a progressive increment in DNA content along the culture periods, with the exception of day 3. Despite the differences not being statistically significant between control PCL NFM and PCL-PEO NFM after PEO dissolution, the latter presents higher cell proliferation, which indicates easier access of inner surfaces for cells to proliferate into, compared with the PCL NFM. In addition, these results confirm that the PEO dissolution did not negatively affect cell proliferation or its viability.

\section{Conclusion \& future perspective}

We demonstrated the efficacy of a dual composition strategy to increase the pore size and solve the low cell infiltration capacity on random electrospun nanofiber meshes. This strategy consists of producing a dual composition nanofiber mesh and selectively removing one of the polymeric fibers (PEO), leaving the other fraction intact (PCL). It was observed that this method does indeed increase the pore size without major alterations of the mesh structure. Pore size measurements showed a significant increase of pore size (doubling) in those meshes when compared with control PCL NFM. The biologic assays demonstrated that the cells were not only able to proliferate into the nanofibrous scaffold, but were also capable of migrating to the opposite side of the mesh.

The strategy herein proposed for the pore size increment of electrospun nanofiber meshes allows a fully cellularized electrospun mesh to be obtained. Considering the promising biological results with a human osteoblastic cell line, further studies with primary cells are envisaged to confirm the biological functionality of these enhanced pore size electrospun meshes. Consequently, this approach can be followed to successfully overcome one of the most critical limitations of the electrospun meshes aimed for the regeneration of $3 \mathrm{D}$ tissues, namely bone, cartilage or full thickness skin wounds.

Financial \& competing interests disclosure The authors have no relevant affliations or financial involvement with any organization or entity with a financial interest in or financial conflict with the subject matter or materials discussed in the manuscript. This includes employment, consultancies, honoraria, stock ownership or options, expert testimony, grants or patents received or pending, or royalties.

No writing assistance was utilized in the production of this manuscript. 
Executive summary

" Electrospinning of a dual composition nanofiber mesh (i.e., polycaprolactone and poly[ethylene oxide]), followed by selective removal of the poly(ethylene oxide) fibers, has been demonstrated.

- Morphological characterization of the final mesh, after dissolution of the poly(ethylene oxide) fraction, demonstrated a significant increment in pore size.

Structural properties of the remaining polycaprolactone fibers were maintained, resembling the morphology of native extracellular matrix.

- Osteoblastic cells colonize the inner regions of the enhanced porous electrospun mesh and migrate/penetrate through its full thickness.

- Cell viability and proliferation were not affected by the highly porous nanofiber mesh structure.

- The proposed method can be used to intentionally control the pore size of electrospun scaffolds.

The postprocessing step does not involve any extra component that could eventually compromise the cellular behavior.

A fully celularized electrospun nanofiber mesh was obtained, appropriate for tissue engineering applications.

\section{Ethical conduct of research}

The authors state that they have obtained appropriate institutional review board approval or have followed the principles outlined in the Declaration of Helsinki for all human or animal experimental investigations. In addition, for investigations involving human subjects, informed consent has been obtained from the participants involved.

\section{Bibliography}

Papers of special note have been highlighted as: " of interest

"n of considerable interest

1 Langer R, Vacanti JP: Tissue engineering. Science 260(5110), 920-926 (1993).

2 Hutmacher DW: Scaffolds in tissue engineering bone and cartilage. Biomaterials 21(24), 2529-2543 (2000).

3 Agrawal CM, Ray RB: Biodegradable polymeric scaffolds for musculoskeletal tissue engineering. J. Biomed. Mater. Res. 55(2), 141-150 (2001).

4 Sachlos E, Reis N, Ainsley C, Derby B, Czernuska JT: Novel collagen scaffolds with predefined internal morphology made by solid freeform fabrication. Biomaterials 24(8), 1487-1497 (2003).

5 Wallace DG, Rosenblatt J: Collagen gel systems for sustained delivery and tissue engineering. Adv. Drug Deliv. Rev. 55(12), 1631-1649 (2003).

6 Lu Q, Ganesan K, Simionescu DT, Vyavahare NR: Novel porous aortic elastin and collagen scaffolds for tissue engineering. Biomaterials 25(22), 5227-5237 (2004).

7 Endres M, Salgado AJ, Kaps C et al.: Osteogenic induction of human bone marrow-derived mesenchymal progenitor cells in novel synthetic polymer-hydrogel matrices. Tissue Eng. 9(4), 689-702 (2003).

8 Tolaimate A, Desbrieres J, Rhazi M, Alagui A: Contribution to the preparation of chitins and chitosans with controlled physico-chemical properties. Polymer 44(26), 7939-7952 (2003).
9 Reis CC, Tuzlakoglu K, Yang K, Haj AE, Reis RL: Influence of porosity/ fiber diameter on the degradation of chitosan fiber-mesh scaffolds. J. Mater. Sci. Mater. Med. 18, 195-200 (2007).

10 Malafaya PB, Pedro AJ, Peterbauer A, Gabriel C, Redl H, Reis LR: Chitosan particles agglomerated scaffolds for cartilage and osteochondral tissue engineering approaches with adipose tissue derived stem cells. J. Mater. Sci. Mater. Med. 16, 1077-1085 (2005).

11 Salgado AJ, Gomes ME, Chou A, Coutinho OP, Reis LR, Hutmacher DW: Preliminary study on the adhesion and proliferation of human osteoblasts on starch-based scaffolds. Mater. Sci. Engl. 20(1-2), 27-33 (2002).

12 Gomes ME, Ribeiro AS, Malafaya PB, Reis RL, Cunha AM: A new approach based on injection moulding to produce biodegradable starch-based polymeric scaffolds: morphology, mechanical and degradation behaviour. Biomaterials 22(9), 883-889 (2001).

13 Balmayor ER, Marques AP, Azevedo HS, Reis RL: A novel enzymatically-mediated drug delivery carrier for bone tissue engineering applications: combining biodegradable starch-based microparticles and differentiation agents. J. Mater. Sci. Mater. Med. 19(4), 1617-1623 (2008).

14 Liu LS, Thompson AY, Heidaran MA, Poser JW, Spiro RC: An osteoconductive collagen/hyaluronate matrix for bone regeneration. Biomaterials 20 (12), 1097-1108 (1999).

15 Borzacchiello A, Mayol L, Ramires PA et al.: Structural and rheological characterization of hyaluronic acid-based scaffolds for adipose tissue engineering. Biomaterials 28(30), 4399-4408 (2007).

16 Chen LJ, Wang M: Production and evaluation of biodegradable composites based on phbphv copolymer. Biomaterials 23(13), 2631-2639 (2002).
17 Martins A, Araújo JV, Reis RL, Neves NM: Electrospun nanostructured scaffolds for tissue engineering applications. Nanomedicine 2(6), 929-942 (2007).

18 Zhang Y, Lim CT, Ramakrishna S, Huang ZM: Recent development of polymer nanofibers for biomedical and biotechnological applications J. Mater. Sci. Mater. Med. 16, 933-946 (2005).

19 Ashammakhi N, Ndreu A, Piras AM et al.: Biodegradable nanomats produced by electrospinning: expanding multifunctionality and potential for tissue engineering. J. Nanosci. Nanotech. 6, 2693-2711 (2006).

20 Martins A, Pinho ED, Faria $S$ et al.: Surface modification of electrospun polycaprolactone nanofiber meshes by plasma treatment to enhance its biological performance. Small 5(10), 1195-1206 (2009).

21 Salgado AJ, Coutinho OP, Reis LR: Bone tissue engineering: state of the art and future trends. Macromol. Biosci. 4(8), 743-765 (2004).

22 Alberts B, Johnson A, Lewis J, Raff M, Roberts K, Walter P: Molecular Biology of the Cell. (4th Edition). Garland Science, New York, NY, USA (2002).

23 Martins A, Reis RL, Neves NM: Electrospinning: processing techinque for tissue engineering scaffolding. Int. Mater. Rev. 53(5), 257-274 (2008).

24 Zagris N: Extracellular matrix in development of the early embryo. Micron. 32(4), 427-438 (2001).

25 Tang ZG, Black RA, Curran JM, Hunt JA, Rhodes NP, Williams DF: Surface properties and biocompatibility of solvent-cast poly(caprolactone) films. Biomaterials 25(19), 4741-4748 (2004).

26 Mikos AG, Bao Y, Cima LG, Ingber DE, Vacanti JP, Langer R: Preparation of poly(glycolic acid) bonded fiber structures for cell attachment and transplantation. J. Biomed. Mater. Res. 27, 183-189 (1993). 
27 Kim BS, Mooney DJ: Engineering smooth muscle tissue with a predefined structure. J. Biomed. Mater. Res. 41, 322-332 (1998).

28 Rodrigues MT, Leonor IB, Viegas CAA, Dias IR, Gomes ME, Reis RL:

Osteoconductive scaffolds obtained by means of $i$ situ surface functionalization of wet-spun fibre meshes for bone regeneration applications. Tissue Eng. A 14(5), 765 (2008).

29 Gomes ME, Godinho JS, Tchalamov AM, Cunha AM, Reis RL: Alternative tissue engineering scaffolds based on starch: processing methodologies, morphology, degradation and mechanical properties. Mater. Sci. Engl. 20, 19-26 (2002).

30 Mooney DJ, Baldwin DF, Shu NP, Vacanti JP, Langer R: Novel approach to fabricate porous sponges of poly(D, L-lactic-co-glycolic acid) without the use of organic solvents. Biomaterials 17(14), 1417-1422 (1996).

31 Shea LD, Wang D, Franceschi RT, Mooney DJ: Engineered bone development from a pre-osteoblast cell line on threedimensional scaffolds. Tissue Eng. 6(6), 605-617 (2000).

32 Mao JS, Zhao LG, Yin JY, Yao KD: Structure and properties of bilayer chitosan-gelatin scaffolds. Biomaterials 24(6), 1067-1074 (2003).

33 Ferreira BM, Sousa RA, Reis RL: Development of novel carrageenan scaffolds for tissue engineering using rapid prototyping. Tissue Eng. 14(5), 837-838 (2008).

34 Landers R, Hubner U, Schmelzeisen R, Mulhaupt R: Rapid prototyping of scaffolds derived from thermoreversible hydrogels and tailored for applications in tissue engineering. Biomaterials 23(23), 4437-4447 (2002).

35 Lam CXF, Mo XM, Teoh D, Hutmacher DW: Scaffold development using $3 \mathrm{D}$ printing with a starch-based polymer. J. Mater. Sci. Eng. 20, 49-56 (2002).

36 Martins A, Chung S, Pedro AJ et al:: Hierarchical starch-based fibrous scaffold for bone tissue engineering applications. J. Tissue Eng. Regen. Med. 3(1), 37-42 (2009).

37 Li M, Mondrinos MJ, Ganghi MR, Ko FK, Weiss AS, Lelkes PI: Electrospun protein fibers as matrices for tissue engineering. Biomaterials 26, 5999-6008 (2005).

38 Townsend-Nicholson A, Jayasinghe S: Cell electrospinning: A unique biotechnique for encapsulating living organisms for generating active biological microthreads/scaffolds. Biomacromolecules 7, 3364-3369 (2006).

"- This study demonstrates the feasibility of using coaxial electrospinning technology to produce composite microthreads with living cells.
39 Stankus JJ, Guan J, Fujimoto K, Wagner WR: Microintegrating smooth muscle cells into a biodegradable, elastomeric fiber matrix. Biomaterials 27(5), 735-744 (2006).

40 Doshi J, Reneker DH: Electrospinning process and applications of electrospun fibers. J. Electrostat. 35(2-3), 151-160 (1995).

41 Li D, Xia Y: Electrospinning of nanofibers: reinventing the wheel? Adv. Mater. 16(14), 1151-1170 (2006).

"- Comprehensive review on the electrospinning technique and its applications.

42 Eichhorn SJ, Sampson WW: Statistical geometry of pores and statistics of porous nanofibrous assemblies. J. R. Soc. Interface 2 , 309-318 (2005).

43 Nam J, Huang Y, Agarwal S, Lannutti J: Improved cellular infiltration in electrospun fiber via engineered porosity. Tissue Eng. 13(9), 2249-2257 (2007).

- Research paper describing the incorporation of leachable salt particles into several layers of electrospun nanofiber meshes as a strategy to allow cell infiltration.

44 Lee HY, Lee JH, An IG et al: : Electrospun dual-porosity structure and biodegradation morphology of montmorillonite reinforced PLLA nanocomposite scaffolds. Biomaterials 26, 3165-3172 (2005).

45 Kim G, Kim W: Highly porous 3D nanofiber scaffold using an electrospinning technique. J. Biomed. Mater. Res. Part B 81(1), 104-110 (2007).

- Research article demonstrating the use of chemical blowing agents to enhance the porosity of electrospun nanofiber meshes.

46 Lannutti J, Reneker D, Ma T, Tomasko D, Farson D: Electrospining for tissue engineering scaffolds. Mater. Sci. Engl. 27, 504-509 (2007).

47 Baker BM, Gee AO, Metter RB et al:: The potential to improve cell infiltration in composite fiber-aligned electrospun scaffolds by the selective removal of sacrificial fibers. Biomaterials 29(15), 2348-2358 (2008).

"- Experimental work reporting considerable cell infiltration from the two seeded surfaces into the central region of aligned nanofiber meshes.

48 Martins A, Cunha J, Macedo F, Reis RL, Neves NM: Improvement of polycaprolactone nanofibers topographies: testing the influence in osteoblastic proliferation. Presented at: 2006 NSTI Nanotechnology Conference and Trade Show. Boston, MA, USA, 7-11 May 2006.
49 She FH, Tung KL, Kong LX: Calculation of effective pore diameters in porous filtration membranes with image analysis. Robot. Comp. Integr. Manufact. 24, 427-434 (2008).

50 Farone A, Magazú S, Maisano G, Migliardo P, Tettamanti E, Villari V: The puzzle of poly(ethylene oxide) aggregation in water: experimental findings J. Chem. Phys. 10(3), 1801-1806 (1999).

51 Zhang YZ, Su B, Venugpal J, Ramakrishna S, Lim CT: Biomimetic and bioactive nanofibrous scaffolds from electrospun composite nanofibers. Int. J. Nanomed. 2(4), 623-638 (2007).

52 Bahatia SK, Smith JL: Geotextile characterization and pore size distribution: Part iii. Comparison of methods and application to design. Geosynth. Int. 3(3), 301-328 (1996).

53 Ramakrishna S, Fujihara K, Teo WE, Lim TC, Ma Z: An Introduction to Electrospinning and Nanofibers. World Scientific Publishing, Singapore (2005).

-1- Comprehensive book extensively covering most of the relevant aspects of the electrospinning technology.

54 Jena A, Sanders H, Miller J, Wimberly R: Comparison of mercury porosimetry and flow porometry for the testing of battery separator materials. Presented at: Proceedings of the 16th Annual Battery Conference on Applications and Advances. Long Beach, CA, USA, 9-12 January 2001.

55 Tzezana R, Zussman E, Levenberg S: A layered ultra-porous scaffold for tissue engineering, created via hydrospinning method. Tissue Eng. C 14 (2008).

- Reports an improved electrospinning set-up and, consequently, an alternative technique to produce nanofiber meshes with increased pore size.

56 Cui W, Li X, Zhou S, Weng J: Degradation patterns and surface wettability of electrospun fibrous mats. Polym. Degrad. Stab. 93(3), 731-738 (2008).

57 Bhattarai SR, Bhattarai N, Yi HK, Hwang PH, Cha DI, Kim HY: Novel biodegradable electrospun membrane: scaffold for tissue engineering. Biomaterials 25, 2595-2602 (2004). 